\title{
A qualitative study of 2Create: A mental health service user-led art group
}

\author{
Ceri Wilson and Lyn Kent
}

Ceri Wilson (corresponding author), Faculty of Health, Social Care and Education, Anglia Ruskin University, Bishop Hall Lane, Chelmsford, Essex, CM1 1SQ, United Kingdom. Email: ceri.wilson@anglia.ac.uk. Phone:+44 (0)845 1964189.

Lyn Kent, Faculty of Health Social Care and Education, Anglia Ruskin University, Bishop Hall Lane, Chelmsford, Essex, CM1 1SQ, United Kingdom. Email: lyn.kent@anglia.ac.uk. Phone: +44 (0)845 1964806

\begin{abstract}
Background: 2Create is a mental health service user-led art group in the UK established by graduates of Open Arts, a community arts and mental health project. The study aimed to explore group members' experiences over its first year.
\end{abstract}

Methods: Semi-structured interviews were conducted with five current and one former member of 2Create.

Results: Key themes related to organisation (evolving; flexibility; finance; leadership challenges), the studio environment, personal gains (social inclusion; self-esteem; well-being) and future plans (increasing membership; exhibitions; funding applications; social events).

Conclusion: The gains reported indicate that 2Create is beneficial to its members. Although a number of challenges were identified, all participants identified personal and group-wide gains and emphasised that challenges are to be expected when setting up a new group. The key implication for independent mental health user-led arts groups is that support is needed in the early stages and that independence can then be achieved with time.

Keywords: Mental health, participatory arts, peer support, service user-led groups.

\section{Introduction}

User-led groups, also referred to as self-help, mutual-aid, or peer-support groups, comprise people with a shared problem or experience coming together for mutual support (e.g. Elsdon, Reynolds, \& Stewart, 2000; Seebohm et al., 2013; Wilson, 1994). Whilst professionals may provide initial support, these groups are organised by and for their members (e.g. Boyce, Munn-Giddings, Smith \& Campbell, 2010; Munn-Giddings \& McVicar, 2006; Wilson, 1998). The number of user-led groups is rising (Munn-Giddings \& McVicar, 2006), taking educational, social or creative forms (e.g. Seebohm et al., 2013; Tyldesley \& Phillips, 2009).

Research has found numerous benefits to user-led group members, including improved health, wellbeing, self-esteem, confidence, skills, and social support (e.g. Kryouz, Humphreys \& Loomis, 2002; Pistrang, Barker \& Humphreys, 2008; Seebohm et al., 2013). Members of mental health user-led groups have been found to experience increased social support, quality of life, health and wellbeing (e.g. Boyce et al., 2010; Nelson, Ochocka, Janzen \& Trainor, 2006). However, challenges have also been identified around funding (e.g. 
Seebohm et al., 2013) and leadership (Boyce et al., 2010; Seebohm et al., 2013). Challenges have been found in balancing the tension between being user-led (where both members and co-ordinators are equally involved in decision-making), and user-managed (where coordinators predominantly run the group: Boyce et al., 2010). Research has also found that being a co-ordinator is emotionally demanding and time-consuming (Seebohm et al., 2013).

In recent years UK Government has promoted the value of user-led groups (e.g. Department of Health, 2007a; 2007b; 2009; Prime Minister’s Strategy Unit, 2005); however, these groups remain under-researched in the UK (Borkman \& Munn-Giddings, 2008; Chaudhary, Avis \& Munn-Giddings, 2010; Seebohm et al., 2013), have a low profile and are little understood (Seebohm et al., 2013).

Mental health service user-led arts groups can be found in the UK, but there is a distinct lack of research exploring their value. However, one study by Aston (2013) found that with support, individuals with mental health difficulties experienced significant benefits from arts engagement in a visual arts group. Crucially, with time they required less support and were willing to take on responsibilities which enabled them to become an independent organisation.

This article outlines the findings from a research study exploring a mental health service userled arts group: 2Create. 2Create is an independent studio group of artists who are graduates of Open Arts, a community arts and mental health project established in 2008 by the South Essex Partnership University NHS Foundation Trust (SEPT). Open Arts offer 12-week visual and performing arts courses to mental health service users and others at risk of mental ill health, including carers. Course attenders are found to significantly improve in mental wellbeing and social inclusion (e.g. Margrove, SE-SURG, Heydinrych \& Secker, 2013; Secker, Loughran, Heydinrych \& Kent, 2011); however, a need for a longer-term option has been identified. In 2012 SEPT, Essex County Council (ECC) and the Association for Cultural Advancement through Visual Art (ACAVA) established an Open Arts Studio, where course completers could attend a six-month art studio placement at the Hadleigh Old Fire Station (HOFS). After its first year the studio had achieved its aim of providing opportunities for members to pursue their art-making independently and offered longer-term benefits in mental wellbeing and social inclusion (Wilson, Secker, \& Kent, 2014). However, the majority of studio members wished that the placement could go on longer and expressed concerns about it ending. An opportunity to rent a studio directly above the HOFS studio later arose, and a few HOFS members decided to group together to form an independent user-led arts group based in the studio. The studio lease officially commenced in September 2013. Initial support around setting up 2Create was given by Open Arts and ECC.

This article describes the findings from six interviews with a purposive sample of 2Create members. Interviews were conducted one year on from the official start of the group, with the aim of hearing from members about their experience of involvement, any benefits and challenges, and their future plans.

\section{Method}

\section{Procedure}

The Chair of 2Create was contacted and asked if the group would be interested in taking part in research exploring their experiences of membership, to which the group responded 
positively. The researchers obtained funding for six interviews from the Anglia Ruskin University (ARU) Faculty of Health, Social Care and Education Scholarship and Research Funds. After receiving ethical approval from the relevant ARU Department Research Ethics Committee the following were given to the Chair to distribute to all current members and any contactable former members:

- Invitation packs

- Reply slips asking for demographical information (age, gender) and whether they were a current or former member or held a position of responsibility in the group

- $\quad$ Pre-paid stamped addressed envelopes for return to the researchers.

Ten current and former members responded and six were selected using purposive sampling. Selection was based on achieving the broadest range of individuals in terms of age and gender. Those who responded were contacted and thanked and interview dates were set up for those selected. A semi-structured interview schedule was developed, covering their experience of art before 2Create, how they came to join, their involvement, their feelings about their involvement, what they thought good about 2Create, what they thought could be improved, any challenges faced by the group, and what they saw as the future of the group. Private interviews took place either in the 2Create studio or at ARU Chelmsford and were recorded and transcribed.

\section{Participants}

Participants comprised three males and three females, one aged 30-39, one aged 40-49, three aged 50-65, and one aged over 65. One male and one female held posts of responsibility in 2Create. Five were current members and one was a former member.

\section{Data analysis}

Thematic analysis techniques were used to identify themes. The analysis went through the steps of familiarisation, initial coding, searching for themes based on initial coding, review of themes, theme definition and labelling (Braun \& Clarke, 2006). The analysis was data rather than theory driven, and themes were identified in an inductive 'bottom-up' way.

\section{Results}

The following sections present participants' views in relation to: the organisation of the group, the studio environment, personal gains, and future development. A number of challenges were identified which are incorporated into the themes. Where extracts from the notes are used to illustrate themes three dots (...) indicate that material less relevant to the theme has been omitted.

\section{Organisation}

\section{Evolving: forming, storming and norming}

The majority of those interviewed explained that the group evolved over the first year of its operation, in response to challenges that had arisen along the way. As one interviewee put it: 
...when you form any group you've got the forming, storming, norming stages... (Participant 4)

Some challenges that arose in the group's first year led to some members leaving, but others pulled together to develop the group in response to these challenges:

...there was a disagreement...then we decided that...if something happens...the committee...give a warning... we sort of put a structure in place. And that's helped that everyone knows now, like this is what you have to do, this is the guidelines everyone's decided and you sort of obey it. (Participant 1)

...this incident that took place...had quite an impact on things, but the others, you know, they carried on and they soldiered on... (Participant 4)

The majority of those interviewed also explained that despite these difficulties things had progressed and the group was now running much more smoothly:

You have a couple of incidents with anyone and you just have to work through them, and I think there's different stages of when you're setting up stuff, and always at the beginning there's hiccups, but now it's coming up to a year, you know, those are mostly ironed out. (Participant 1)

\section{Flexibility}

Despite initial intentions for members to attend one set day a week, a key theme to emerge was that there was flexibility around the days attended, which was perceived as very beneficial:

...I think if you have it rigid with people that have mental health, it gets too much. So it's a bit more flexible...you can actually choose the day you're going, or you chose the day at the beginning, and if you want to change it then as long as you speak to the committee you can sort of change it. (Participant 1)

...I come in about three hours or three and a half hours...a day on each occasion, twice a week...flexibility is very beneficial to us. (Participant 5)

\section{Finance}

Five out of six interviewees mentioned the financial aspects of 2Create. The rent of the studio and how the group covered the cost by paying $£ 12.50$ each a month was described. Positive financial aspects of 2Create membership were mentioned:

....it gives you the opportunity to do something that you wouldn't necessarily be able to afford on your own... (Participant 1 )

...I think we're very lucky to have that studio... at a very reasonable rent...they $[A C A V A]$ presumably subsidise the rents to make it available to groups like us. (Participant 3) 
However, half of those interviewed mentioned some of the financial struggles associated with membership, both personally and for prospective members:

...those of us who are not financially capable...would like to get...financial assistance from somewhere...so that we can continue to be members... (Participant 5)

I think at the moment there's probably people that would like to join it, but it is the finance at the moment that is making them sort of hold back... (Participant 4)

Two of those interviewed related financial concerns to membership, for example:

...we've taken on the studio, we've got a regular rent to pay. Now we can pay that rent with...eight members, on the current level of contributions, but if people drop out then obviously it becomes a difficult thing... (Participant 3)

However, one member thought that the benefits of 2Create membership outweighed its financial costs:

...we don't mind spending money...on the dues, because of the benefits we get, derive from it, which are immense. (Participant 5)

\section{Leadership}

A few of those interviewed explained that there had been changes in the initially appointed committee during the first year, due to two members leaving. The current committee members who had been voted in comprised a treasurer, chair and secretary. A number of challenges with being a committee member were identified by former and present committee members alike, for example:

...when we have...problems we [committee members] quite often get together....and talk about them, and we end up having to deal with them. And that's all quite a strain, you know, it's not what I would ideally want to be doing... (Participant 3)

The challenges associated with being a committee member could also impact on the time to carry out artwork, as explained by a former member:

...I was thinking, all I'm getting is a lot of grief and no art, no art time...it just sort of seemed sad...that that had happened...I thought well, what is the point in not being able to do my art, just having all these feelings and being bogged down with all this administrative stuff? (Participant 4)

The strain on committee members when trying to resolve problems was exacerbated by the fact that they were not trained in running an organisation:

...I don't think there's anyone there who's actually had experience of running an organisation...It's dealing with the interpersonal relations and things I think, I don't feel at all qualified to deal with that...there's a bit of a dilemma about how we can deal with it... (Participant 3) 
In identifying the strains associated with leadership, a few interviewees compared the group to Open Arts, where there were designated experienced managers to deal with arising situations. Some of those interviewed emphasised the responsibility and commitment needed by the 2Create management team in sometimes difficult situations, and with little back-up other than mutual support of other team members who may have differing ideas of how the group was run:

...Open Arts...were providing a studio manager...so all you had to do was turn up...you don't have to think about any of the admin side of it... But with 2Create it's the group runs it themselves and... we've got a treasurer, a secretary, and a chairman, and if you're part of that you're concerned with all the things...that have to be done....and what the problems might be at the time, so you've got that side of it which you didn't have... with Open Arts...that's much more difficult, that can be quite a... worrying... aspect of it. (Participant 3)

...with 2Create...it's sort of a democratic institution, people interpret democracy in different ways, some people think, well, you elect a chairman and they run it, and they make all the decisions, and other people think, well, we should all be deciding what to do... (Participant 3)

...suddenly you've not got your safety net of all the organisers of Open Arts, and all of a sudden if we've got a problem with somebody being not well or something's going on, who ultimately is the one to support, who do you turn to? (Participant 4)

This final participant went on to explain that this was particularly a concern for managing a group with mental health needs:

...we were....all people with needs that needed the support of Open Arts, and still having the same issues, were then set free, but there isn't really the mental health backup there...but when you are in...the elected management team, everyone is focusing on you being the one to sort all the problems out...we're ultimately all responsible for what goes on and, you know, that's why it's a collaborative group. But they still have to have someone to go to...you're the one that's going to have to sort the problems out... (Participant 4)

A few interviewees explained that Open Arts helped 2Create in its early development, but given the need for 2Create to be a separate group this was no longer the case meaning that some members had to accept responsibilities in order for the group to continue to function:

...we've had help from Open Arts...but they have indicated that...they can't do that all the time, that we're a separate group and we have to sort of deal with it our own way and on our own...but the trouble is...there are always other problems come up you see, and that's when it sort of gets difficult, I think, because we haven't got the people there who actually helped us get it started... (Participant 3)

\section{Studio Environment}

\section{Location}


Five of those interviewed discussed the implications of the studio being directly above the Open Arts studio. Two interviewees viewed this close proximity to Open Arts positively:

...it's actually quite nice being above them [Open Arts], I mean if you are up here on your own and you want someone to talk to like, you can always go down and have a chat to them. And because you know most of the tutors and that down there, yeah, you don’t feel you're imposing. (Participant 6)

...I'm lucky because I do downstairs [tutor for Open Arts] on a Thursday, and if anyone pops in they just give me a little wave and, you know, it's just nice to see those people... (Participant 2)

However, three other interviewees were more wary about crossing over into Open Arts given the separate nature of the two groups, for example:

...I think we've had also a bit of a warning from... Open Arts...that they don't really want it to be seen as two parts of the same organisation, they want it to be seen as separate...I'm now a little wary... about how long I can stay there, because I don't want to feel that I'm sort of a person from another organisation sort of using their facilities, or intruding on them you see. (Participant 3)

\section{Physical environment}

All of those interviewed discussed the physical environment of the 2Create studio. There were no negative comments, with all expressing positive opinions about the studio's layout, furniture, storage, size, and lighting. The most frequent comments related to the space that each individual member had, for example:

...you can store stuff there...you've got that space...if they're working on an oil painting or something you can't really take that home so it stays there, and yeah, it's stored until it's dry... And we've got a bit of wall space as well, so we can put our pictures up... (Participant 2)

....it gives you a bit of freedom, I mean normally I've been working from my house... and there is no space there. At least when I come here I've got space and I can...put all my oils out and everything else like and not have to worry about them, and then at the end of the day you just clear up and that's it, you're done. (Participant 6)

\section{Personal Gains}

\section{Social relations}

The most frequently referenced gains were social in nature, with all participants citing social benefits from membership. Social benefits included sharing ideas and learning from one another:

...we have encouragement from each other, you know, and...if you have any problem with what you are doing, you ask someone to help you and, you know, it gives you encouragement that way and advice. (Participant 5) 
Four participants also described the benefits of being in a group with likeminded people who shared an understanding of mental health, for example:

...it's nice to...just sort of go there and be with people that understand and you can just sit quietly or you can listen to the radio or you can talk. (Participant 1)

I find it really relaxing to be around other...people that have all got some sort of, you know, problems and stuff... (Participant 4)

Members also described how 2Create had increased their social activity and decreased their social isolation:

...it's a good social thing, you know, if you're feeling unwell you can go there and you know if you're meeting someone there, you can arrange to meet someone there and have a chat and do some art. It's just nice. (Participant 1)

I mean before I started doing the art I was actually becoming a bit of a recluse, like, and I was sitting in my room on my own. It's brought me out quite a bit and, yeah, it's actually like turned me round quite a bit. (Participant 6)

2Create was also thought to provide a sense of belonging, with some describing it as a family, a team, and/or a community:

It's like a community...everybody there is friendly...you can feel safe and do your work...it gives you, like a sense of belonging...it gives you part of being a team. (Participant 6)

...there's some lovely people... when we're there it is supportive and people do get on well, and it's like a little mini family... (Participant 2)

However, as one member explained, the social aspect of 2Create could have both positive and negative sides:

...you've got the social element, so you get the chance to talk to people and that's great. Sometimes it's difficult to actually, you know, resolve differences and things...there's two sides to it, you know. (Participant 3)

Related to this less positive aspect, the majority of those interviewed referred to at least one negative incident between members. Some acknowledged that difficulties working together arose from differing personalities and different ideas about how the studio should be organised:

...some of the people....are very quiet...very self-contained, don't want to talk about anything to do with their problems or their illness, they just want to go in and get on with their art...but [other person] is quite a loud personality...so passionate...clash of personalities I think, some of the time. (Participant 4)

... adjusting to this being their space and how they feel it should be, and other people having a different slant on it...you know, we'd rather have it like that... (Participant 2) 


\section{Self-esteem and pride}

Five out of six participants reported gains in their self-esteem and/or pride in what they had achieved either as a group or as individual artists. Pride in the group having been set up by and run by those with, or at risk of, mental health difficulties was expressed by three of those interviewed, for example:

...I think initially the fact that it was formed is a fantastic thing, to feel that, you know, a group of people...that were quite emotional or quite sad... were able to participate in getting this thing up and running as a group...you just feel like, how proud to say I've actually got a studio that I rent and I participate in...I can only say I'm thrilled, I'm going to get emotional in a minute! (Participant 4)

Personal pride and increased self-worth resulting from the actual production of art work, which could be given to family members and friends, was also expressed:

...the work I do, I give to friends and relatives...I like it because it makes me feel that I'm valuable, I'm making some valuable contribution to other people's lives...because it gives you self-worth, you know, when you give your work to people and they're saying they appreciate the work you have done... (Participant 5)

\section{Wellbeing}

Five participants described increases in their general wellbeing from 2Create participation, for example:

2Create has been very beneficial to me...I derive a lot of emotional benefit... (Participant 5)

Because I've suffered from depression for many years and lack of confidence and basically like it was helping me come out of my shell... art is a very good medium for transferring how you feel... (Participant 6)

Being able to carry out artwork in the 2Create studio was particularly beneficial for taking members away from their problems, both physically and mentally:

...when I'm at home there's all sorts of other things that I'm conscious of... whereas if I go to the studio that's what I'm there for, that's the only thing I'm sort of actually thinking about, and I can put all the other things aside. So that's a very positive thing...doing the art...takes you away from your problems... (Participant 3)

I think for me personally it takes me away, I focus just on the art, I find it very relaxing. (Participant 4)

\section{Future Developments}

\section{Personal development}

Four of those interviewed expressed ways in which they were hoping to develop personally in the future. Two participants were hoping to become a volunteer for Open Arts in addition to 
being a member of 2Create. One participant explained that one of their own future aims was to attend 2Create more regularly and become more involved in the group. This participant also looked beyond 2Create and expressed a desire to study art at college in the future:

...what I would like to do is actually go back to college...And, I don't know, just some qualifications or whatever else like, and then going on to probably teaching art as well. (Participant 6)

Another participant was keen to expand their personal art skills through taking part in 2Create:

... at the moment I'm concentrating on water colour, but I've asked some of the members who are doing acrylic to introduce me to acrylics as well, I would like in the near future to start using acrylics. (Participant 5)

\section{Development of 2Create}

All participants expressed plans and ideas for the future development of 2Create. The most frequently mentioned was increasing the number of members, with all six mentioning this. The motivation for expanding the membership included financial security for the group, reduced costs of membership, and making full use of the studio space:

What I would like to see is a few more members so that we've got enough members to make...full use of the space we've got... and give a bit more security, and if somebody did decide to leave it wouldn't leave us, you know, unable to pay the rent. It might even mean we could reduce the rent... (Participant 3)

Four participants mentioned plans for offering trial memberships with a 'pay-as-you-go' system, the aim being to give potential future members a taster, which may encourage future commitment from those who are perhaps unsure about committing straight away:

....if they haven't made up their minds to give them the opportunity to...pay as you go...for about a period of six weeks and then afterwards they have to make up their minds...This is in order to maintain the membership of 2Create into the future, for a long time. (Participant 5)

The second most frequently mentioned plan for the future was to display the group's art at exhibitions. Some participants expressed a general desire for exhibiting, whilst others referenced specific exhibiting opportunities, such as the Hadleigh Art Trail, an annual community event for local artists, photographers and community art groups. Displaying their work at such exhibitions was perceived as something they would not have had the opportunity to do as individuals:

I mean as an individual you would never get into an art trail, so as a group like, we can do that. (Participant 6)

Three participants also explained the group’s plans to apply for funding, for example: 
...we're going to try for sort of funding from places as well...we're just trying to work out which places you can apply...it's all in the pipeline, it's just sort of taking it...as it comes really. (Participant 1)

Two of those interviewed mentioned plans for a future social event for 2Create members. This was viewed as important for getting the members together as many attended the studio on different days. The opportunity for members to get together socially as opposed to at member meetings when certain issues would need to be discussed relatively formally was also viewed as important, although finding a day everyone was free was acknowledged as a challenge:

...we need to do this social evening...it will be a bit more informal....that's what I'm currently trying to sort, but it's just trying to find a day that everybody's available. (Participant 2)

A few other ideas for the future of 2Create were suggested by individual participants, such as putting on workshops, and having an expert come in to teach members new skills. One participant was also keen for more groups to grow out of 2Create:

What I'm hoping is that there'll be a 3Create and a 4Create...say for example a group of people that come from Southend area, if they were able to rent a little studio, because there are these places around...perhaps Brentwood, Thurrock, Southend...Billericay... (Participant 4)

However, one participant emphasised that although the earlier mentioned ideas for the group were good things to do, the primary aim of the group should be to simply keep the studio going, keep the group settled, and continue to provide that space for people to do their artwork:

...the main thing is just to have the studio there and people getting into the habit of coming in and using it...the main purpose is just to provide a space...the opportunity to exhibit every now and again... would be an important thing because, you know, it's always great to have what you've done seen by people...to really get the full satisfaction out of it...But that's secondary to actually the main aim of keeping the studio going and just providing that space for people. (Participant 3)

This participant also explained that the main challenge with implementing all of the aforementioned ideas would be that someone would have to organise them, putting additional responsibilities onto the group's already stretched committee:

...this is one of the worries that people come up with ideas... which is like a nice idea in theory, but somebody's actually got to actually do that and organise it... (Participant 3)

\section{Discussion}

The results reported here represent an exploratory study of 2Create, a mental health user-led arts group, over its first year of operation. The aims of the study were to explore members' experiences of involvement in 2Create, any benefits and challenges experienced, and any future plans. This was a small-scale study based on interviews with only six current and former members, however the sample comprised balanced numbers of men and women and 
was broadly representative of the group in terms of age. The results provide an early indication that 2Create provides multiple benefits to its members, however they also highlight the many challenges associated with the running of a user-led art group comprising mental health service users.

The six individuals interviewed had different experiences of involvement in 2Create which depended largely on the individual's role, although on the whole everyone spoke positively about the group. All participants spoke very highly of their experience of Open Arts, identifying numerous benefits they had gained. Following on from the conclusions of the earlier HOFS studio evaluation (Wilson et al., 2014), where participants expressed great concern about their opportunity for art-making ending, all of those interviewed explained that their motivation for setting up 2Create was because of the benefits they had gained from Open Arts and their desire to see those benefits continue. Some of the gains identified from Open Arts in previous evaluations (Margrove et al., 2013; Secker et al., 2011; Wilson et al., 2014) were also identified as a result of 2Create: social gains such as sharing ideas, socialising with each other, and sharing a mutual understanding of mental health; reduced social isolation; increased self-esteem and pride; and increased mental wellbeing. Some additional gains from 2Create were also mentioned, such as pride not only in the production of artwork but also in the setting up and running of an art group. Added flexibility in 2Create was also a unique benefit of the group.

In addition to the extra benefits from 2Create compared with Open Arts, participants also identified a number of additional challenges, the most prominent of which related to leadership, coinciding with the experiences of other user-led groups (e.g. Boyce et al., 2010; Seebohm et al., 2013). Whereas Open Arts had designated experienced managers to deal with arising situations, 2Create was run by the members themselves who had no experience or training and suddenly lacked a safety net. Some of those interviewed emphasised the responsibility and commitment needed by the 2Create management team in sometimes difficult situations, and with little back-up other than mutual support of other team members who may have differing ideas of how the group is run. This meant that 2Create membership involved more than the production of artwork and the benefits associated with that, and involved not only positive but also negative social aspects.

It was clear that 2Create had had to face a number of challenges in its first year, but the group was still functioning after a year. It had evolved in response to challenges, members were still enthusiastic to keep it going and had exciting plans for the future: exhibiting art work, applying for funding, putting on social events and more. A few members were also keen to see other similar groups in other locations in Essex grow. This has already begun as there is now a newly formed community group called 'The Loose Screws Amateur Dramatic Society' whose founder members have all participated in Open Arts Drama and Arts courses.

2Create members had a number of future plans for the group, but they also had concerns for the future, the most prominent being the recruitment of new members in order to obtain financial security and to make full use of the studio space. Another concern was the need for someone to take responsibility for the organisation of new initiatives. At the time of writing initial plans to make full use of the studio space have been put in place, but leadership and support remains an ongoing issue.

Aston (2013) found that with time mental health service users partaking in a visual arts group required less support and were willing to take on responsibilities which enabled them to 
become an independent organisation. This corresponds with the 2Create journey, moving from Open Arts introductory courses where tutors teach specific arts skills in planned programmes, to the HOFS studio placement where participants can undertake independent art-making but with support available from professional artists, to 2Create, an independent art group. The key implications for the running of independent mental health user-led arts groups, are that support is needed in the early stages and that independence can then be achieved with time. In order to help prevent individuals being thrown in the deep end without a safety net, training could be useful for founder members in the very early stages. Useful topics for training include how to manage an organisation, how to manage a group with mental health needs, how to write a constitution, how to apply for funding, and how to conduct members meetings. These are all areas which were identified as challenging by 2Create members.

The numerous gains reported indicate that 2Create is very beneficial to its members, and provides an opportunity for the benefits from Open Arts to continue beyond the introductory course and studio placement. An earlier evaluation (Wilson et al., 2014) demonstrated that the HOFS studio placement offered longer-term benefits in terms of wellbeing and social inclusion for Open Arts introductory course completers, and the present findings demonstrate that likewise 2Create provides longer-term benefits for HOFS studio placement completers. It is therefore of key importance for 2Create to be able to continue its good work, and remain a permanent fixture, something which has previously been called for by Open Arts graduates (Wilson et al., 2014). Although a number of challenges associated with the setting up and running of 2Create have been identified, all of those interviewed have identified personal and group-wide gains from membership and have emphasised that these challenges are to be expected when setting up a new group. As one participant explained:

I like to think that I've been honest with you, you know, I could have sat here and said, oh, everything's been a bowl of cherries all the way through, but life isn't like that and you would not expect it to be like that. I mean anything that I've participated in or I've seen, they've all had their little ups and downs, that is how things are, you know. So none of those things are negatives, they're not negatives at all, they're just observations really. (Participant 4)

\section{References}

Aston, T. (2013). Art in recovery: from participation to independence. Mental Health and Social Inclusion, 17(3), 140-146.

Borkman, T., \& Munn-Giddings, C. (2008). The contribution of self-help groups and organizations to changing relations between patients/consumers and the health care system in the US and UK. In: S. Chambre \& M. Goldner (Eds.), Patients, consumers and civil society: US and international perspectives, Vol. 10. Advances in Medical Sociology (pp. 127-150). Bingley: Emerald Group Publishing.

Boyce, M., Munn-Giddings, C., Campbell, S., \& Smith, L. (2010). Innovatory features and challenges facing mental health user-led organisations. Mental Health Review, 15(2), 34-42. 
Braun, V., \& Clarke, V. (2006). Using thematic analysis in psychology. Qualitative Research in Psychology, 3(2), 77-101.

Chaudhary, S., Avis, M., \& Munn-Giddings, C. (2010). The life-span cycle and life-cycle of self help groups: a retrospective study of groups in Nottingham, UK. Health and Social Care in the Community, 18(4), 346-354.

Department of Health. (2007a). User Led Organisation (ULO) Project Policy. London: Department of Health.

Department of Health. (2007b). Commissioning Framework for Health and Well-being. London: Department of Health.

Department of Health. (2009). Putting People First: Working together with user-led organisations. London: Department of Health.

Elsdon, K., Reynolds, J., \& Stewart, S. (2000). Sharing Experience, Living and Learning: A Study of Self Help Groups. London: Community Matters.

Kyrouz E., Humphreys K., \& Loomis C. (2002). A review of research on the effectiveness of self help mutual aid groups. In: B.J. White and E.J. Madara (Eds.), The Self Help Sourcebook: Your Guide to Community and Online Support Groups, 7th edn (pp. 7186). Denville, NJ: American Self Help Group Clearinghouse.

Margrove, K. L., SE-SURG (South Essex Service User Research Group)., Heydinrych, K., \& Secker, J. (2013). Waiting list-controlled evaluation of a participatory arts course for people experiencing mental health problems. Perspectives in Public Health, 133, 2835.

Munn-Giddings, C., \& McVicar, A. (2006). Self-help groups as mutual support: what do carers value? Health and Social Care in the Community, 15(1), 26-34.

Nelson, G., Ochocka, J., Janzen, R., \& Trainor, J. (2006). A longitudinal study of mental health consumer/survivor initiatives: part 2 - a quantitative study of impacts of participation in new members. Journal of Community Psychology, 34(3), 261-272.

Pistrang, N., Barker, C., \& Humphreys, K. (2008). Mutual help groups for mental health problems: a review of effectiveness studies. American Journal of Community Psychology, 42, 110-121.

Prime Minister's Strategy Unit. (2005). Improving the Life Chances of Disabled People. London: The Stationery Office.

Secker, J., Loughran, M., Heydinrych, K., \& Kent, L. (2011). Promoting mental well-being and social inclusion through art: evaluation of an arts and mental health project. Arts \& Health: An International Journal for Research, Policy and Practice, 3(1), 51-60.

Seebohm, P., Boyce, M., Chaudhary, S., Avis, M., \& Munn-Giddings, C. (2013). The contribution of self-help/mutual aid groups to mental wellbeing. Health \& Social Care in the Community, 21(4), 391-401. 
Tyldesley, R., \& Phillips, L. (2009). Beat the Blues - a self-help group for parents experiencing post-natal depression. Life in the Day, 13(2), 9-12.

Wilson, C., Secker, J., \& Kent, L. (2014). Arts participation, mental well-being and social inclusion: Mixed methods evaluation of an Open Arts studio for people with mental health needs. Journal of Applied Arts \& Health, 5(3), 343-354.

Wilson, J. (1994). Two Worlds: Self help groups and professionals. London: BASW, Venture Press.

Wilson, J. (1998). Self Help Groups: Getting started and keeping going (2nd edition). Nottingham: RA Wilson.

Word count: 6479 